\title{
Textural and morphological studies of transition metal doped SBA-15 by co-condensation method
}

\author{
P H K CHARAN and G RANGA RAO* \\ Department of Chemistry, Indian Institute of Technology Madras, Chennai 600 036, India \\ e-mail: grrao@iitm.ac.in
}

MS received 5 July 2014; revised 2 January 2015; accepted 3 January 2015

\begin{abstract}
The 3d transition metals were incorporated into SBA-15 matrix by co-condensation synthesis method. Very low concentrations of metals were introduced into silica framework by maintaining the metal to silica ratio in the synthesis gel at 0.01 . The difference in hydrolysis rates of metal and silica precursors have led to textural modifications while demonstrating the structural integrity akin to pristine SBA-15. The physicochemical properties obtained offer some insights into the P123 micelle aggregation and mechanism of formation of silica network in the presence of metal salts under similar synthesis conditions of pure SBA- 15 . The metal doping into SBA-15 leads to increased pore diameters. Higher lattice constants $\left(\mathrm{a}_{0}\right)$ observed in these samples are attributed to the increased pore wall thickness. The significant retention of the hexagonal mesostructure seen in LXRD indicates diminutive influence of metal salts at lower concentrations. Macroscopic morphologies studied by SEM show the formation of spheres along with conventional fibre-like rods.
\end{abstract}

Keywords. Transition metal; SBA-15; co-condensation; spherical morphology; textural properties.

\section{Introduction}

Over the past two decades, MCM-n and SBA-n series have generated immense interest in the synthesis of periodic mesoporous silica materials which made remarkable progress in diverse applications such as organic transformation, ${ }^{1}$ enzyme immobilization, ${ }^{2}$ drug delivery, ${ }^{3}$ chromatography ${ }^{4}$ and sensors. ${ }^{5}$ In this perspective, SBA-15 has been extensively studied owing to its flexible nature in tuning the textural and structural configurations. ${ }^{6,7}$ In particular, the transition metal grafted SBA-15 materials have shown promising results in heterogeneous catalysis ${ }^{8,9}$ and bio-sensor applications. ${ }^{10}$ The enhanced catalytic activities are attributed to effective diffusion of the substrate molecules through the pores and can access directly to the active centres. But the active metal centres that are incorporated into the porous network by co-condensation (one-pot) method usually disrupts the structural ordering thereby creating different morphological structures.

Supra-molecular self-assembly has initiated a new research era in the synthesis of versatile functional porous materials as it offers better control at molecular level during the bottom-up construction process. The typical SBA-15 consists of long range ordered

\footnotetext{
*For correspondence
}

fibre like morphology in the order of few micrometres $(\mu \mathrm{m})$ length. However subtle changes in the synthesis approach lead to various morphogenesis products. In addition to the nature of the pore system, i.e., pore size, shape and connectivity, mesoporous materials with short and open channels are well explored because they are more favourable for the mass transfer. The macroscopic particles such as short rods, small spheres and crystal-like particles ease the intraparticle diffusion thereby being more useful in guest molecule encapsulation ${ }^{11}$ and chromatographic separation studies. ${ }^{12}$ Thus different practical applications require corresponding chemically significant morphological architectures of mesoporous materials. Even though some exotic morphological SBA-15 structures such as sphere, fibre, doughnut, rod, rice-shape, rope, egg-sausage, gyroid, platelet and discoid-like shapes have been reported, the design and synthesis is still an intriguing topic. ${ }^{13,14}$ Sayari et al., have proposed that under static conditions and in the absence of inorganic salt additives, monodispersed short SBA15 rods are formed when temperature at the initial stage not exceeding $60^{\circ} \mathrm{C}^{15}$ Zhao et al., have emphasized that long fibres with uniform diameter are produced by employing TMOS (tetramethoxy silane) as the silica source which undergoes faster hydrolysis. ${ }^{16}$ The gyroid and discoid-like morphological SBA-15 are formed by phase separation of these macroscopic structures aggregated around aqueous inorganic electrolytes 
such as $\mathrm{MgSO}_{4}$ and $\mathrm{Na}_{2} \mathrm{SO}_{4}$ solution droplets from the assembling inorganic oxide-block copolymer surfactant interface during evaporation of the ethanol. Highly ordered circle meso channels, designated as doughnutlike SBA-15 are achieved using DMF (N,N-dimethyl formamide) as a co-solvent. However, recently similar doughnut-like SBA-15 was prepared by Lee et al., at higher temperature $\left(65^{\circ} \mathrm{C}\right)$ and fast stirring rates $(500 \mathrm{rpm})$ which they attributed to combination of hindered growth and shear stress. ${ }^{14}$ The addition of CTAB (hexadecylammonium bromide), a cationic surfactant has induced more curvature consequently creating uniform mesoporous hard silica spheres. Therefore the surface curvature energy at the interface of inorganic silica and organic block copolymer species is crucial for the final morphology of mesoporous SBA-15.

The formation of SBA-15 mesostructure is controlled by various synthesis parameters like temperature, ${ }^{17,18}$ shearing, ${ }^{14}$ inorganic components ${ }^{19,20}$ and additives. ${ }^{21,22}$ The complex interactions among the different species in the synthetic mixtures, such as condensation rate of silica species, shape of surfactant micelles, concentration of inorganic salts and stirring rate also affect the textures of mesoporous SBA-15. ${ }^{13}$ General shape-selective morphogenesis methodology for SBA-15 material has been demonstrated by Lee et al., in which they anticipated the hindered particle growth under high temperature and slow stirring results in SBA-15 particles with dramatically reduced diameters. ${ }^{14}$ The temperature rise from $20^{\circ} \mathrm{C}$ to $45^{\circ} \mathrm{C}$ has no influence on hexagonal symmetry of SBA-15 mesostructure ordering but showed substantial difference in its macrostructure. ${ }^{17}$ The gradual phase transformation from spheres to long rods with increase in temperature was observed and found $45^{\circ} \mathrm{C}$ as the upper limit for hexagonal region in SBA-15 synthesis phase diagram which is in accordance with the P123 phase diagram. Indeed the temperature effect on ripening step in SBA-15 synthesis indicates the size and shape of hybrid micelles prior to flocculation. ${ }^{18}$ The primary particles obtained from elongated micelles gradually transform to thread-like micelles with increase in temperature. Nevertheless the ripening step is determined to be critical in the evolution of final morphology of SBA-15 mesostructure. It is interesting to note the promoting role of two inorganic salt pairs $\mathrm{KCl} / \mathrm{NH}_{4} \mathrm{~F}^{19}$ and $\mathrm{NaCl} / \mathrm{MCl}_{\mathrm{x}}{ }^{20}$ in the mesostructure ordering. The electrolytes (alkali salts) improved structural ordering in both the cases whereas the $\mathrm{MCl}_{\mathrm{x}}$ performs self-generated acid role whilst the $\mathrm{F}^{-}$dramatically enlarges the pore sizes respectively. Greater the alkane solubilizates in the complex emulsion system, higher the transformation from rod-like to globular aggregates which thus favours the formation of short-pore SBA-15 platelets with the tunable aspect ratios. ${ }^{19}$ In addition, the temperature affects the micelle formation of amphiphilic block copolymer and the hydrophobic character becomes more significant via endothermic dehydration of PPO groups at higher temperature.

The Lewis and Brønsted acid sites created by the direct incorporation of $3 \mathrm{~d}$ transition metal into SBA15 framework have been explored for various organic transformation reactions. ${ }^{8,10,23-27}$ Nevertheless, introducing the metal species into SBA-15 silica network is very difficult due to the easy dissociation of metaloxo species under strong acidic hydrothermal conditions. The considerable difference in the hydrolysis rates and ionic strengths between the metal additives and silica precursors may affect the macroscopic structure of SBA15. In addition, the interfacial chemistry at amphiphilic block copolymer surfactant and inorganic species further stimulate the morphological changes. In a recent report, Lee et al., have investigated the interaction mechanism of transition metal with the Pluronic surfactant, P123 and the decrease in the aspect ratio is ascribed to the metal-chelating surfactant micelle template effect. ${ }^{28}$ In this context, we have focused the confinement effect of $3 \mathrm{~d}$ transition metal species in porous silica network of SBA-15 during cocondensation process. The physico-chemical properties of metal modified SBA-15 materials are well characterized by XRD, $\mathrm{N}_{2}$ adsorption-desorption isotherms, UV-Vis DRS, $\mathrm{H}_{2}$-TPR, SEM and TEM techniques. The metal doped SBA-15 samples showed enlargement in the pore diameters but the substantial enhancement in lattice constants are contributed by the amazingly high pore wall thickness. The remarkable retention of the hexagonal mesostructure ordering shows diminutive influence by the addition of metal salts at lower concentrations although the macroscopic morphologies show formation of spheres along with conventional fibre-like rods.

\section{Experimental}

\subsection{Materials}

Analytical grade tetraethylorthosilicate $\left(\mathrm{Si}\left(\mathrm{OC}_{2} \mathrm{H}_{5}\right)_{4}\right.$, TEOS, 99\%, Merck), non-ionic triblock co-polymer Pluronic P123 (poly(ethyleneoxide)-block-poly(propyleneoxide)-block-poly(ethyleneoxide)-block, $\mathrm{EO}_{20} \mathrm{PO}_{70}$ $\mathrm{EO}_{20}, \mathrm{MW}=5800$, Aldrich), hydrochloric acid, all the metal precursors as nitrate salts (SD Fine Chemicals Limited) except vanadium (vanadyl sulphate) and were purchased and used as such. 


\subsection{One-pot synthesis of SBA-15 and metal modified SBA-15}

Mesostructured SBA-15 and 3d transition metal incorporated SBA-15 materials $\left(\mathrm{M}^{\mathrm{n}+} / \mathrm{SBA}-15\right.$, where $\mathrm{M}=\mathrm{V}$, $\mathrm{Cr}, \mathrm{Mn} \mathrm{Fe}, \mathrm{Co}, \mathrm{Ni}, \mathrm{Cu}$ and $\mathrm{Zn}$ ) were hydrothermally synthesized by co-condensation method using triblock copolymer P123 $\left(\mathrm{EO}_{20} \mathrm{PO}_{70} \mathrm{EO}_{20}\right)$ as the template material. The pure silica, SBA-15 was prepared by conventional procedure as reported. ${ }^{6}$ However, the metal precursor was added to surfactant solution along with TEOS in this method. All the metal slats employed are nitrate precursors except vanadium (vanadyl sulphate). In a typical synthesis, $4 \mathrm{~g}$ of P123 was dissolved under stirring in $30 \mathrm{~mL}$ of deionized water at room temperature and then $120 \mathrm{~mL}$ of $2 \mathrm{M} \mathrm{HCl}$ was added. Required metal salts were dissolved in $10 \mathrm{~mL}$ of ethanol and added to tetraethylorthosilicate (TEOS). The metal-TEOS mixture was ultrasonicated for 10 min for homogenization. The mixture was then added to the P123 polymer solution under constant stirring. The mole composition of the mixture for $4 \mathrm{~g}$ of $\mathrm{P} 123$ was 1 TEOS/0.020P123/0.01 $\mathrm{M}^{\mathrm{n}+} / 5.6 \mathrm{HCl} / 208 \mathrm{H}_{2} \mathrm{O}$. The resultant solution was stirred for $20 \mathrm{~h}$ at $40^{\circ} \mathrm{C}$, followed by aging at $100^{\circ} \mathrm{C}$ for $48 \mathrm{~h}$ under static conditions. The solid product was filtered, washed with deionized water and ethanol, air dried at $80^{\circ} \mathrm{C}$ overnight, and then calcined at $550^{\circ} \mathrm{C}$ for $8 \mathrm{~h}$ in flowing air. The $3 \mathrm{~d}$ transition metal incorporated calcined samples are designated as M/SBA-15 (where $\mathrm{M}=\mathrm{V}, \mathrm{Cr}, \mathrm{Mn} \mathrm{Fe}, \mathrm{Co}, \mathrm{Ni}, \mathrm{Cu}$ and $\mathrm{Zn}$ ) in the text. The structural and textural properties of the calcined M/SBA-15 materials and the effect of metal doping were investigated by various characterization techniques. Nevertheless the TGA characterization was carried out for as-synthesized samples and the samples represented as SBA-15-uc and M/SBA-15-uc accordingly where $\mathrm{M}=\mathrm{V}, \mathrm{Cr}, \mathrm{Mn}, \mathrm{Fe}, \mathrm{Co}, \mathrm{Ni}, \mathrm{Cu}$ and $\mathrm{Zn}$.

\subsection{Characterization methods}

The X-ray diffraction pattern of calcined SBA-15 and metal doped SBA-15 were recorded in the low angle region from $0.5^{\circ}$ to $5.0^{\circ}$ by Bruker AXS D8 Advance diffractometer and at a scan rate of $0.05^{\circ} \mathrm{s}^{-1}$, using $\mathrm{Cu}$ $\mathrm{K}_{\alpha}(\lambda=1.5414 \AA)$ radiation generated at $40 \mathrm{kV}, 30 \mathrm{~mA}$. The specific surface area of SBA-15 and M/SBA-15 were determined by $\mathrm{N}_{2}$ adsorption-desorption experiments carried on an automatic Micromeritics ASAP 2020 analyzer using Brunauer-Emmett-Teller (BET) gas adsorption method at $77 \mathrm{~K}$. The as-synthesized samples were out-gassed at $150^{\circ} \mathrm{C}$ for $12 \mathrm{~h}$ under vacuum before physisorption measurements. The pore size distribution plots were generated from desorption branch of the isotherm by the BJH method considering the cylindrical pore model. The thermogravimetric analysis (TGA) was done on Q-500 Quantachrome (TA-Instruments) in the range of $40-800^{\circ} \mathrm{C}$ in air. Fourier transform infrared (FTIR) spectra were recorded on a Shimadzu FTIR-8100 spectrophotometer using thin wafer containing $1 \%$ of sample in $\mathrm{KBr}$. The surface morphology and elemental analysis of the calcined materials were studied using a FEI Quanta 200 Scanning electron microscope (SEM). SEM images were obtained from the powder samples dispersed on carbon tape. Diffuse reflectance UV-Vis spectra were collected from 200 to $700 \mathrm{~nm}$ on a JASCO V-570 spectrophotometer equipped with an integrating sphere. A white reflectance standard (barium sulphate) was used as a reference. $1.0 \mathrm{~cm}$ path length quartz cuvettes were used for analyzing solutions. $\mathrm{H}_{2}$-TPR experiments for all the samples were carried out on Micromeritics Chemisorb 2750 apparatus using TCD detector and a fixed-bed flow micro-reactor in the temperature range of $25-750^{\circ} \mathrm{C}$. Prior to $\mathrm{H}_{2}$-TPR experiments, $100 \mathrm{mg}$ of sample was degassed at $500^{\circ} \mathrm{C}$ for $1 \mathrm{~h}$ in $25 \mathrm{~mL} / \mathrm{min}$ flow of helium and oxygen gases. The samples were cooled to room temperature and $\mathrm{H}_{2}$-TPR experiment was carried out in a flow of $5 \% \mathrm{H}_{2}$ in $\mathrm{Ar}$ at a heating rate of $20^{\circ} \mathrm{C} / \mathrm{min}$ up to about $750^{\circ} \mathrm{C}$. A gas condenser trap $\left(-80^{\circ} \mathrm{C}\right)$ is placed prior to the TCD to remove water.

\section{Results and Discussion}

\subsection{Structural analysis by low angle powder XRD}

The characteristic XRD pattern in low angle region $\left(2 \theta<3^{\circ}\right)$ of all the calcined SBA-15 and M/SBA-15 samples which are shown in figure 1 have revealed the ordered nature of SBA-15 pores. The intense peak corresponds to (100) reflection along with two very weak peaks which are assigned to (110) and (200) reflections respectively, represents the typical hexagonal lattice of SBA-15 with P6mm symmetry. The diminished intensities of the major reflection evidently suggest a slight collapse in its crystalline nature i.e., mesoporous structural ordering. In general, the addition of metal species to silica precursor in one-pot synthesis method results in isomorphic substitution of heteroatom in silica matrix. However it primarily depends on the hydrolysis rate and coordination environment of inorganic precursors as well as $\mathrm{pH}$ of the synthesis medium. All the metal modified SBA-15 samples, except Ni/SBA15 show significant shift towards lower angles in XRD compared to parent SBA-15 which is prepared under similar conditions. It clearly demonstrates expansion 


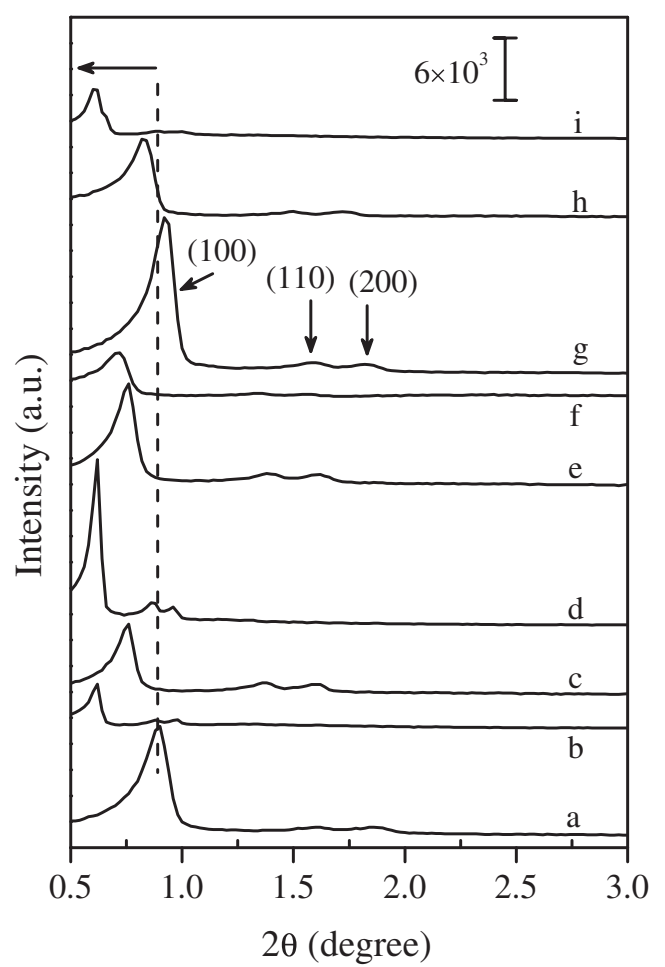

Figure 1. Low angle XRD patterns of SBA-15 and M/ SBA- 15 calcined samples: (a) SBA-15, (b) V/SBA-15, (c) Cr/SBA-15, (d) Mn/SBA-15, (e) Fe/SBA-15, (f) Co/SBA-15, (g) Ni/SBA-15, (h) Cu/SBA-15 and (i) Zn/SBA-15.

in the framework lattice which is attributed to possible incorporation of heteroatom into silica framework. The lattice parameter for a primitive hexagonal lattice is determined by the equation $a_{0}=\frac{2 d}{\sqrt{3}}$, where $\mathrm{d}$ is the inter-planar distance of $d_{100}$ plane and the corresponding values of all samples are summarized in table 1 . It is important to note that the increase in unit cell constant, $a_{o}$ is not systematic with respect to the subsequent ionic radii of metal cations. In order to incorporate transition metal into silica network the metal cation should possess similar ionic radius of $\mathrm{Si}^{4+}(0.40 \AA)$ with tetrahedral geometry. Since, the metal cations exist as either +2 or +3 oxidation state under the low $\mathrm{pH}$ synthesis conditions and the corresponding ionic radii vary from $0.44 \AA$ to $0.78 \AA$ respectively, for the $3 \mathrm{~d}$ transition metal cations. The increase in lattice parameter can be attributed to higher $\mathrm{M}-\mathrm{O}$ (where $\mathrm{M}=\mathrm{V}$, $\mathrm{Cr}, \mathrm{Mn}, \mathrm{Fe}, \mathrm{Co}, \mathrm{Ni}, \mathrm{Cu}$ and $\mathrm{Zn}$ ) bond lengths compared Si-O bond length. ${ }^{23}$ However the difference in hydrolysis and condensation rates of metal species with respect to silica affects the long range mesostructure ordering which is reflected in the figure 1 . Therefore the decrease in intensity is partially attributed to disruption in its long range arrangement. Table 1 depicts the extended lattice constants with larger pore diameters for all the M/SBA-15 samples except Ni/SBA-15 elucidate the consequent effect on enhanced pore walls. The Ni/SBA-15 has shown an unexpected shrinkage in its unit cell constant while the XRD pattern show three well resolved intense peaks. The intensity of an XRD peak is a measure of mesostructure ordering hence it clearly state the Ni/SBA-15 possess significantly wellorganized hexagonal pores. Therefore the decrease in the lattice constant is attributed to possible disruption in inter-particle growth mechanism at macroscopic scale which is in agreement with its morphological evolutions as it created an ordered array of spheres.

\subsection{Textural analysis by adsorption-desorption isotherms}

The $\mathrm{N}_{2}$ adsorption-desorption isotherms of all the calcined samples are shown in the figure 2. According to the IUPAC classification, type IV isotherms are obtained and exhibited H1- type broad hysteresis loop, which is typical for large-pore mesostructured silica materials. The isotherms displayed a sharp increase which is characteristic of capillary condensation of nitrogen within cylindrical mesopores with uniform

Table 1. Textural and structural characteristics of calcined samples of SBA-15 and M/SBA-15 (M = V, Cr, Mn, Fe, Co, Ni, $\mathrm{Cu}$ and $\mathrm{Zn})$.

\begin{tabular}{|c|c|c|c|c|c|c|c|c|}
\hline Compound & $\begin{array}{c}\text { Surface } \\
\text { area } \\
\mathrm{m}^{2} / \mathrm{g}\end{array}$ & $\begin{array}{c}\text { Micro pore } \\
\text { surface area } \\
\mathrm{m}^{2} / \mathrm{g}\end{array}$ & $\begin{array}{c}\text { Pore } \\
\text { volume } \\
\mathrm{cm}^{3} / \mathrm{g}\end{array}$ & $\begin{array}{l}\mathrm{t} \text {-plot micro } \\
\text { pore volume } \\
\qquad \mathrm{cm}^{3} / \mathrm{g}\end{array}$ & $\begin{array}{c}\text { Pore } \\
\text { diameter } \\
\text { (D) } \AA\end{array}$ & $\begin{array}{c}\text { Planar } \\
\text { distance } \\
\mathrm{d}_{(100)} \AA\end{array}$ & $\begin{array}{c}\text { Lattice } \\
\text { constant } \\
\left(\mathrm{a}_{\mathrm{o}}\right) \AA\end{array}$ & $\begin{array}{c}\text { Wall } \\
\text { thickness } \\
\left(a_{o}-D\right) \AA\end{array}$ \\
\hline SBA-15 & 664 & 221 & 0.68 & 0.10 & 52 & 98 & 113 & 61 \\
\hline V/SBA-15 & 757 & 105 & 0.97 & 0.04 & 62 & 143 & 165 & 103 \\
\hline $\mathrm{Cr} / \mathrm{SBA}-15$ & 831 & 101 & 0.93 & 0.04 & 52 & 117 & 135 & 83 \\
\hline $\mathrm{Mn} / \mathrm{SBA}-15$ & 763 & 70 & 1.11 & 0.03 & 68 & 143 & 165 & 97 \\
\hline $\mathrm{Fe} / \mathrm{SBA}-15$ & 897 & 172 & 1.08 & 0.08 & 59 & 117 & 135 & 76 \\
\hline Co/SBA-15 & 837 & 85 & 1.12 & 0.03 & 68 & 122 & 141 & 73 \\
\hline $\mathrm{Ni} / \mathrm{SBA}-15$ & 783 & 159 & 0.93 & 0.07 & 59 & 94 & 109 & 50 \\
\hline $\mathrm{Cu} / \mathrm{SBA}-15$ & 703 & 66 & 0.92 & 0.03 & 62 & 106 & 122 & 60 \\
\hline $\mathrm{Zn} / \mathrm{SBA}-15$ & 836 & 86 & 1.14 & 0.03 & 66 & 138 & 159 & 93 \\
\hline
\end{tabular}




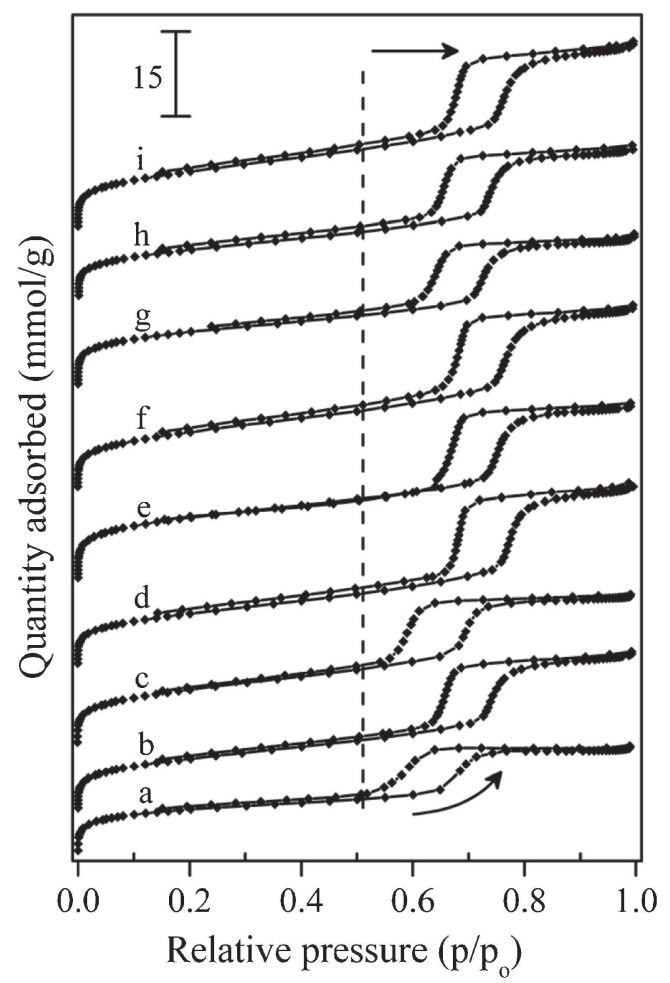

Figure 2. BET isotherms of SBA-15 and M/SBA-15 calcined samples: (a) SBA-15, (b) V/SBA-15, (c) Cr/SBA15, (d) Mn/SBA-15, (e) Fe/SBA-15, (f) Co/SBA-15, (g) Ni/SBA-15, (h) Cu/SBA-15 and (i) Zn/SBA-15.

pore size. The onset point of capillary condensation step indicates the pore diameter, and therefore greater the relative pressure $\left(\mathrm{p} / \mathrm{p}_{\mathrm{o}}\right)$, higher is the pore width. The specific surface area was inferred by Brunauer-EmmettTelleller (BET) mode and the total pore volume was taken from the amount of nitrogen adsorbed at $\mathrm{p} / \mathrm{p}_{\mathrm{o}}=$ 0.98. The calcined SBA-15 sample showed moderate BET surface area, $664 \mathrm{~m}^{2} / \mathrm{g}$ and total pore volume 0.68 $\mathrm{cm}^{3} / \mathrm{g}$. The corresponding micropore surface area and micropore volume are $221 \mathrm{~m}^{2} / \mathrm{g}$ and $0.10 \mathrm{~cm}^{3} / \mathrm{g}$, respectively. As a result the micropore surface area and volume contribution are $33.3 \%$ and $14.7 \%$ with respect to the total surface area and volume. Mesostructure is retained for all the calcined M/SBA-15 samples and they exhibited type IV isotherms with broad H1- type hysteresis loop. However, there is significant loss in their micropore surface area and micropore volume in which Mn/SBA-15 sample shows major loss and possess only $9.2 \%$ and $2.7 \%$ respectively whereas Ni/SBA15 retains as much as $20 \%$ and $7.5 \%$ micropore surface area and volume respectively. Thus it is apparent, that the metal atoms are incorporated into the silica framework in M/SBA-15 samples.

The mean pore diameter and the pore size distribution were calculated from the desorption branch of the isotherm using Barrett-Joyner-Halenda (BJH) method

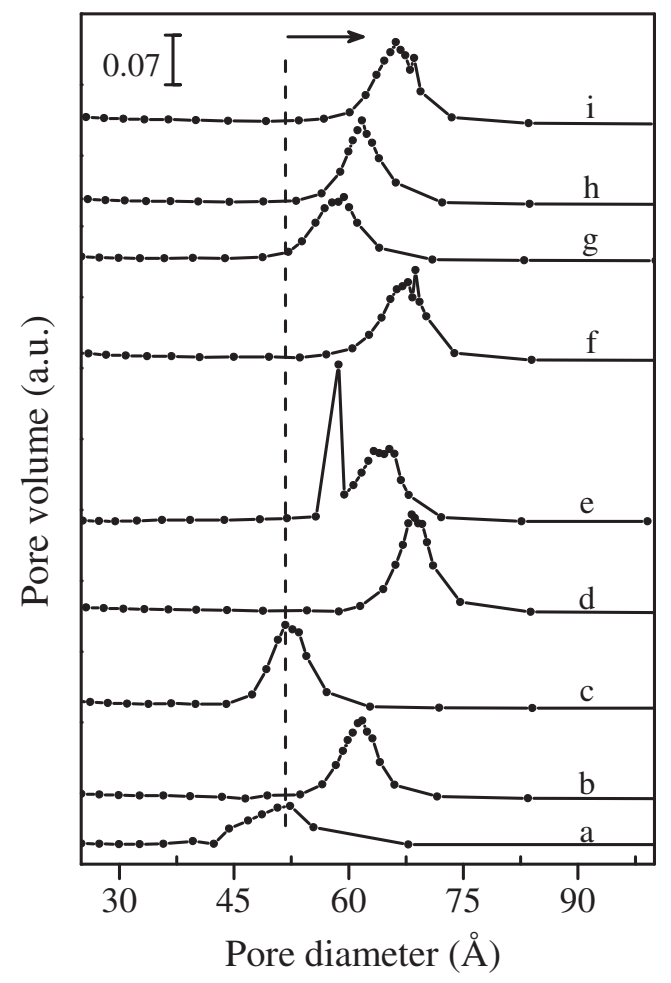

Figure 3. BJH pore size distributions of $\mathrm{SBA}-15$ and M/SBA-15 calcined samples: (a) SBA-15, (b) V/SBA-15, (c) Cr/SBA-15, (d) Mn/SBA-15, (e) Fe/SBA-15, (f) Co/SBA-15, (g) Ni/SBA-15, (h) Cu/SBA-15 and (i) Zn/SBA-15.

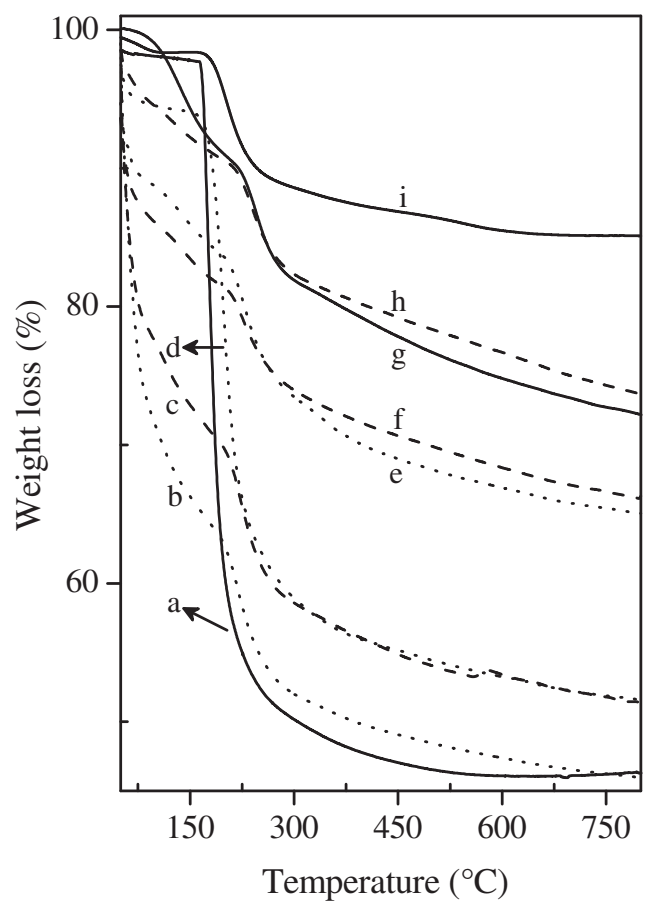

Figure 4. TGA of SBA-15 and M/SBA-15 as-synthesized samples in air: (a) SBA-15-uc, (b) Zn/SBA-15-uc, (c) Fe/SBA-15-uc, (d) Mn/SBA-15-uc, (e) Cr/SBA-15-uc, (f) Co/SBA-15-uc, (g) V/SBA-15-uc, (h) Ni/SBA-15-uc and (i) Cu/SBA-15-uc. 


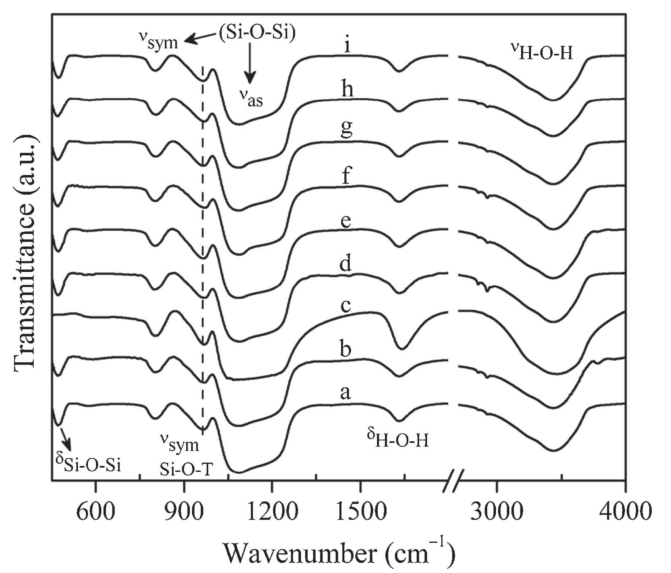

Figure 5. FTIR spectra of SBA-15 and M/SBA-15 calcined samples: (a) SBA-15, (b) V/SBA-15, (c) $\mathrm{Cr} / \mathrm{SBA}$ 15, (d) $\mathrm{Mn} / \mathrm{SBA}-15$, (e) $\mathrm{Fe} / \mathrm{SBA}-15$, (f) $\mathrm{Co} / \mathrm{SBA}-15$, (g) Ni/SBA-15, (h) Cu/SBA-15 and (i) Zn/SBA-15.

whereas the pore wall thickness was obtained by subtracting the pore diameter from the unit cell constant. The pore size distribution of SBA-15 and metal doped SBA-15 calcined samples are shown in figure 3. SBA-15 showed a broad distribution profile with mean pore diameter of $52 \AA$ and a reasonably high pore wall thickness of $61 \AA$. Metal cations doped into SBA-15 has enlarged pore diameters thus confirms the inclusion of metal species into silica framework which earlier substantiated by the shift towards lower angles in the XRD pattern. Moreover the presence of metal salt facilitates uniform pores which are revealed by the symmetrical curves in the figure 3 . The pore wall thickness is one of the crucial factors in the catalytic transformation as it can withstand high pressure reactions. The substantial enhancement of pore wall thickness for metal doped SBA-15 samples clearly illustrated the promoting effect of metal cation on the silica condensation step. The detrimental effect on micropore surface area and micropore pore volume evidently suggest the pore blocking which is attributed to inclusion of metal species in micropores. During the self-assembly process of SBA15 synthesis, the hydrophilic ethylene oxide groups penetrate into condensed silica species occluded at the
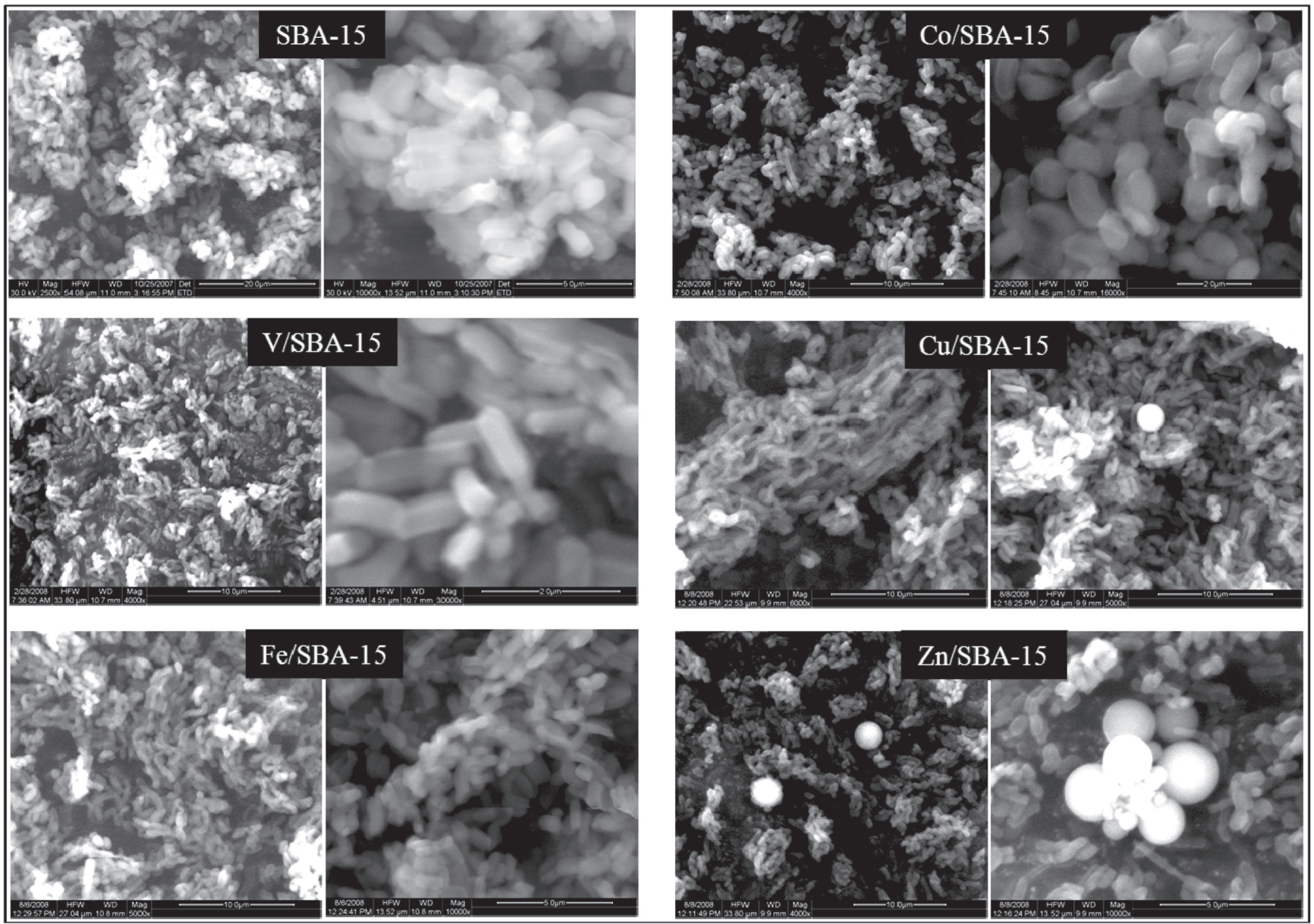

Figure 6. SEM images of calcined SBA-15 and M/SBA-15 $(\mathrm{M}=\mathrm{V}, \mathrm{Fe}, \mathrm{Co}, \mathrm{Cu}$ and $\mathrm{Zn})$ samples with uniform rod shaped array. 
interface which upon calcination generates intrawall micropores. ${ }^{29}$ However the addition of metal salt competes with the silica precursor at the surfactantsolution interface. The strong interfacial interactions of metal species with surfactant may disturb the local hydrolysis and condensation process thereby diminishing the interconnected pore network. The textural properties such as surface area, pore size, pore volume and pore wall thickness is summarized in table 1 . The striking improvement in textural parameters suggests that the metal salts promote the silica condensation as a result possesses thicker pore walls.

\subsection{TG Analysis}

Thermogravimetric curves primarily illustrate the surfactant removal process from the condensed silica structure. Figure 4 shows the decomposition pattern of P123 surfactant from various metal grafted SBA-15 materials prior to calcination. Pure SBA-15 (figure 4a) shows huge and sharp weight loss of $\sim 50 \%$ around $200^{\circ} \mathrm{C}$ indicating the template decomposition. SBA-15 shows typical weight loss pattern in two steps. The initial weight loss at $100^{\circ} \mathrm{C}$ is ascribed to loss of physisorbed water and the huge weight loss around $200^{\circ} \mathrm{C}$ is due to surfactant decomposition. ${ }^{16}$ Even though all the materials prepared under similar conditions, they show different weight losses because the washing treatment employed for as-synthesized samples is not uniform. The as-synthesized samples are washed with ethanol and water mixture several times which varied for each sample. Therefore the consequent leaching of the template into the solution is also varied. However the decomposition temperature remained same at $200^{\circ} \mathrm{C}$ illustrated the similar interaction behaviour of the surfactant with the silica framework.

\subsection{FTIR Study}

The FTIR spectra of calcined SBA-15 and M/SBA15 samples that are shown in the figure 5 elucidate the textural integrity of the M/SBA-15 materials. The

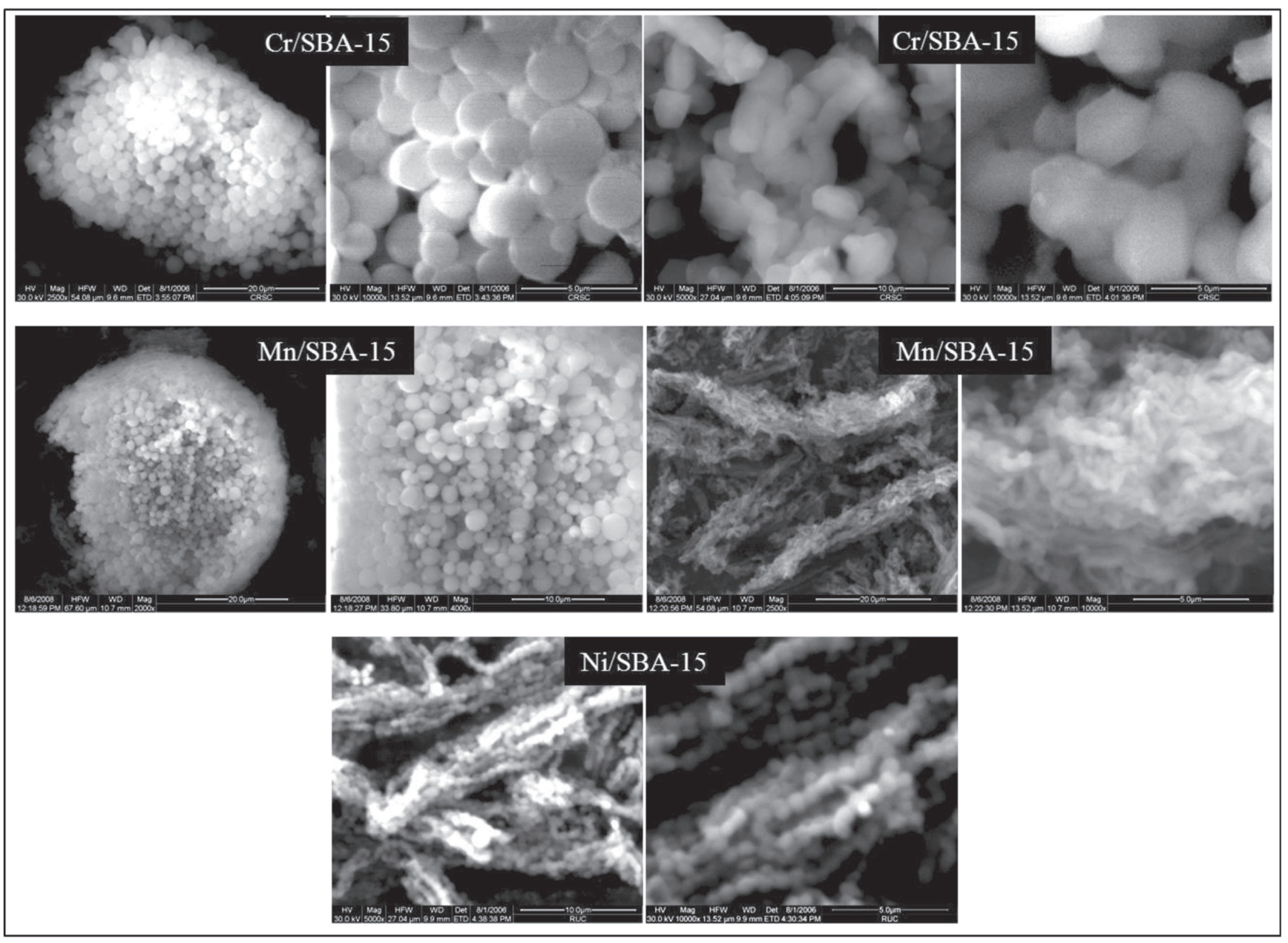

Figure 7. SEM images of calcined M/SBA-15 ( $\mathrm{Cr}$ and $\mathrm{Mn}$ ) samples with spherical aggregation along with rod morphology and array of spheres for Ni/SBA-15. 
bands between 500 and $1200 \mathrm{~cm}^{-1}$ are assigned to silicate framework vibrations. An intense band at 1085 $\mathrm{cm}^{-1}$ is attributed to the asymmetric stretching modes of $\mathrm{Si}-\mathrm{O}-\mathrm{Si}$ and the corresponding symmetric stretching modes are observed at $800 \mathrm{~cm}^{-1}$, whilst the 470 $\mathrm{cm}^{-1}$ is due to bending modes of $\mathrm{Si}-\mathrm{O}-\mathrm{Si}$ groups. A broad envelope observed around $3400 \mathrm{~cm}^{-1}$ is a signature band due to $\mathrm{O}-\mathrm{H}$ stretch resulted from adsorbed water in addition to both surface hydroxyl and bridged hydroxyl groups. Besides, the band corresponds to 1635 $\mathrm{cm}^{-1}$ represents the bending vibrations of $\mathrm{O}-\mathrm{H}$ vibrations present due surface silanol groups. Even though FTIR has no direct evidence of incorporation of metal into the framework, in general, FTIR band around $960 \mathrm{~cm}^{-1}$ in silicate structures is assigned to a lattice defect (Si-O-T, where $\mathrm{T}=$ heteroatom). Hence the shift observed at $960 \mathrm{~cm}^{-1}$ is correlated to the interaction of hetero atom with silicate framework. However in case of metal grafted SBA-15 samples there is no significant shift at $960 \mathrm{~cm}^{-1}$ suggest very little loading of metal cations in SBA-15 framework. The modified SBA-15 samples contain thicker pore walls and the possible confinement of metal species deep in the intrawall micropores besides lower loadings might be reasons for insignificant response in FTIR analysis.

\subsection{SEM study and factors influencing the morphology of $M / S B A-15$}

The SEM images shown in the figure 6 and 7 reveal that there are two different morphologies for the calcined M/SBA-15 samples. The characteristic rod-like morphology of SBA-15 is observed by all the samples except Ni/SBA-15. The dual morphology consists of both rods and spheres are observed in the case of $\mathrm{Cr} / \mathrm{SBA}-15$ and Mn/SBA-15 samples. However it is interesting to note that Ni/SBA-15 sample possess string of spheres. The typical rod like morphology with 2D hexagonal lattice apparently elucidates the formation of characteristic SBA-15 particles. In the M/SBA15 samples the rods are arranged in an array while the spheres are further agglomerated into larger particles. The addition of metal salt induces curvature thereby changing the morphologies. Also, figure 6 and 7 show that irrespective of their morphology, the macroscopic particles are of uniform nature.

The morphology of mesoporous SBA-15 is strongly dependent on the surface curvature energy at the interface of inorganic silica and organic block copolymer species. From the amphiphilic block copolymer point of view, the organic ${ }^{22}$ or inorganic ${ }^{17}$ additives have influenced the micelle aggregation behaviour at molecular level thereby creating various morphogenesis silica materials. The interactions between the surfactant and the inorganic precursor are responsible for the mesoporous materials formation during the self-assembly process. The SBA-15 synthesis follows through a neutral pathway, in which double layer hydrogen bonding is responsible for the cohesiveness between the surfactant and the inorganic precursor. ${ }^{16}$ P123 surfactant always forms spherical micelles and has profound influence by the acid nature on the overall size of the micelles. Moreover, according to Hoffmeister series, the salting-in/chaotropic anions like $\mathrm{NO}_{3}^{-}$have a tendency to confine inside the micelles so that reduces their micelle size. ${ }^{30}$ The surfactant and inorganic precursor interface interactions are better described by considering a core-shell model of the P123 micelles. The $\mathrm{NO}_{3}^{-}$anion has a similar role in all the metal doped SBA-15 sample synthesis mechanism. The competitive interactions among the metal cation and silica precursor during the self-assembly process determine the meso structure formations. At low $\mathrm{pH}$ conditions, both metal and silica precursors possess positive charge and interacts with P123 surfactant through hydrogen

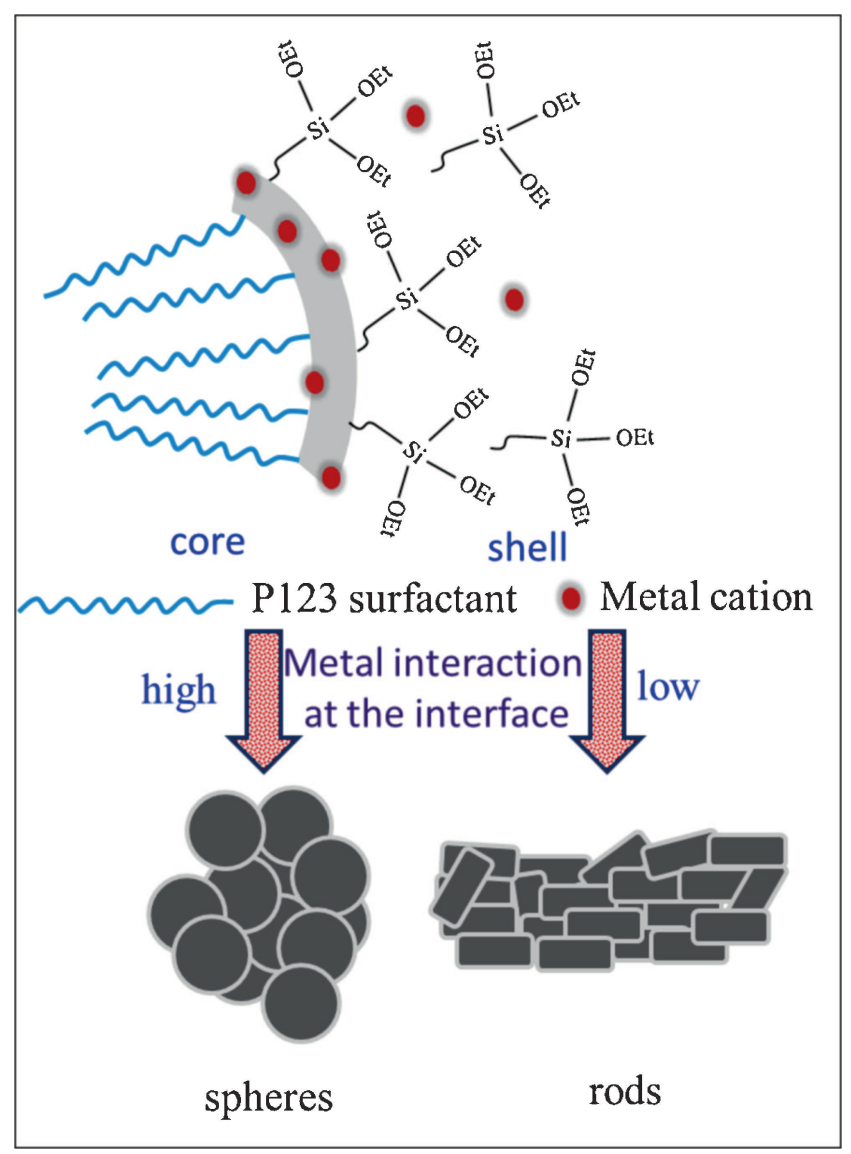

Scheme 1. Plausible interaction of metal cations with surfactant and silica precursor at the interface during the selfassembly process (core-shell model). 
bonding where anions $\left(\mathrm{Cl}^{-}\right.$and $\left.\mathrm{NO}_{3}^{-}\right)$act as a bridge between them. Scheme 1 represents the plausible interaction pathway of metal cations competing with silica species which influences the self-assembly process thus crafting morphogenesis products. The M/SBA-15 samples show significant loss in their micropore surface area and micropore volume has clearly ascertained the strong interaction of the metal species compared to silica precursor.

\subsection{TEM Study}

Figure 8 shows the TEM images of two dimensional hexagonal mesopores for calcined samples of SBA-15, $\mathrm{Cr} / \mathrm{SBA}-15$ and Ni/SBA-15. The images depict the long range order of uniform pores and their perpendicular view clearly illustrates the honey-comb type hexagonal mesopores. These images further substantiate the structural integrity of silicate matrix which preserved even after metal incorporation. Absence of large particles inside or on the external surface of SBA-15 pore channels confirms that either uniform dispersion of metal oxide clusters or incorporation of metal cations into silica framework. Therefore it is apparent that irrespective of their macroscopic morphology all samples possess uniform hexagonal lattice mesostructures.

\section{$3.7 \quad U V$-vis DRS Study}

UV-vis DR spectroscopy is useful in determining the local coordination environment of metal species in a silica network. Figure 9 shows the DR spectra recorded for SBA-15 and M/SBA-15 calcined samples in UVvis region (200-800 nm). All the samples are white in colour and indicate very little loadings of metal into SBA-15 porous silica matrix. The two broad absorption bands with the peak maxima around 238 and $293 \mathrm{~nm}$ are attributed to $\mathrm{O} \rightarrow \mathrm{Si}^{4+}$ charge transfer transitions associated to SBA framework with different degree of condensations of SBA-15. In general, the transition metals show intense absorption bands in the region of 200$400 \mathrm{~nm}$ which is due to ligand to metal charge transfer transitions $\left(\mathrm{O}^{2-} \rightarrow \mathrm{M}^{\mathrm{n}+}\right)$. There is a small shift in the absorption edges of silica framework transitions for the

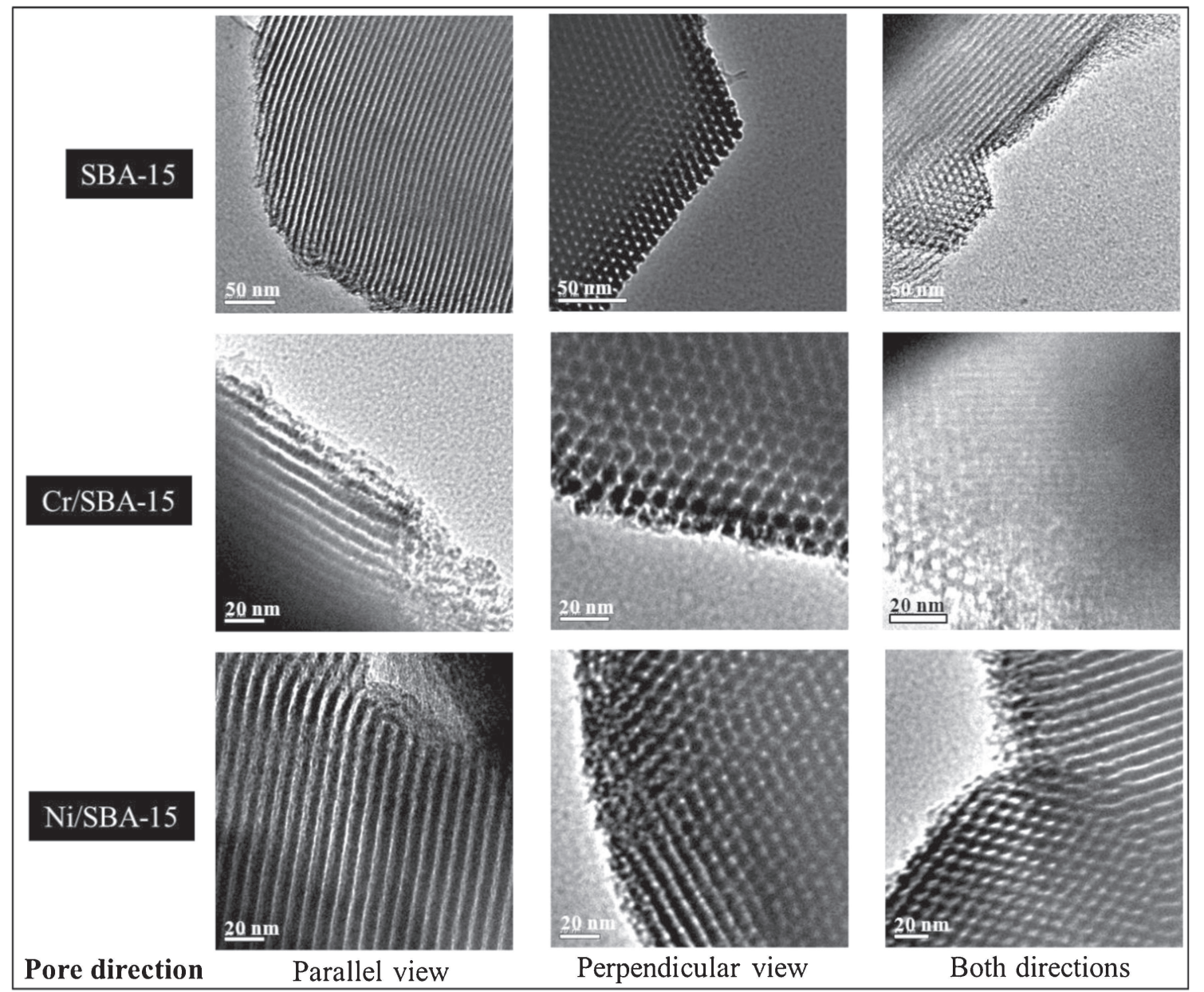

Figure 8. TEM images of calcined SBA-15, Cr/SBA-15 and Ni/SBA-15 samples with both pore directional views. 


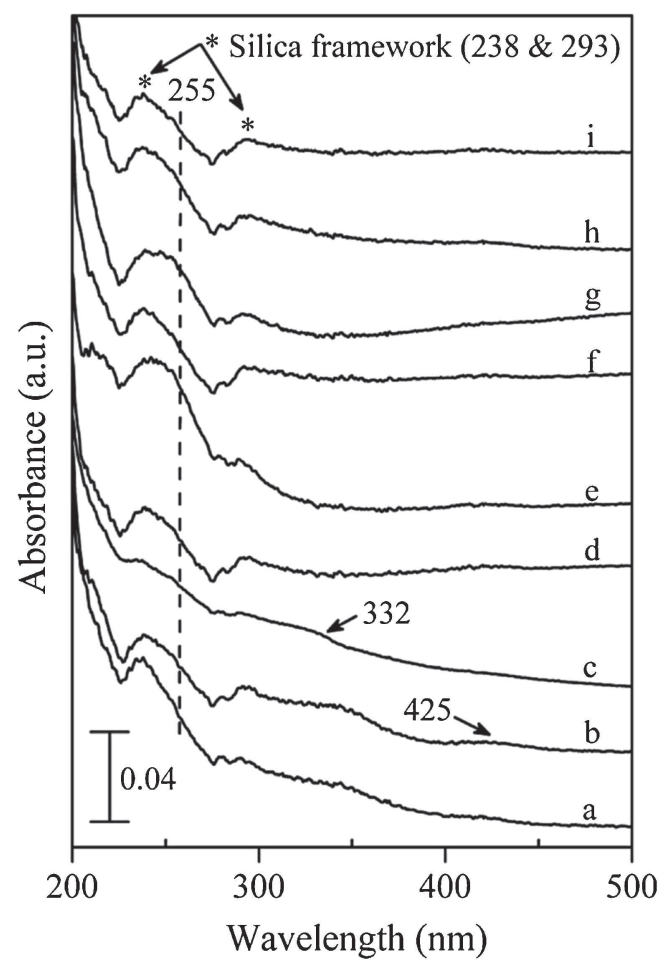

Figure 9. UV-Vis DRS of SBA-15 and M/SBA-15 calcined samples: (a) SBA-15, (b) V/SBA-15, (c) Cr/SBA15, (d) $\mathrm{Mn} / \mathrm{SBA}-15$, (e) Fe/SBA-15, (f) Co/SBA-15, (g) Ni/SBA-15, (h) Cu/SBA-15 and (i) Zn/SBA-15.

metal grafted SBA-15 samples indicating the structural incorporation of metal atoms. The absorption shift is prominent in the case of first band with peak maximum at $\sim 238 \mathrm{~nm}$ where a weak shoulder appears at $255 \mathrm{~nm}$ is ascribed to the charge transfer transitions of isolated metal species. In addition very weak shoulders appear in the visible region which is attributed to metal oxide clusters grafted onto pore walls. The transition in the visible region is due to the possible formation of metal oxide clusters. At low $\mathrm{pH}(\mathrm{pH}<2)$, the transition metal cations endure oligomerization which may be grafted to the surface pore walls.

\section{$3.8 \quad H_{2}-T P R$ Analysis}

The microenvironment of metal in the silica framework and metal to support interaction between the metal particles and the surface of SBA-15 pore walls was investigated using temperature-programmed reduction (TPR). The $\mathrm{H}_{2}$-reduction profiles of the metal grafted SBA-15 calcined samples (M/SBA-15) are shown in figure 10. The reduction profile of calcined SBA-15 sample is also included for comparison studies. Unlike zeolites, the SBA-15 framework is amorphous in nature and so the isomorphic substitution of metal in silica framework does not necessarily be on the surface. The

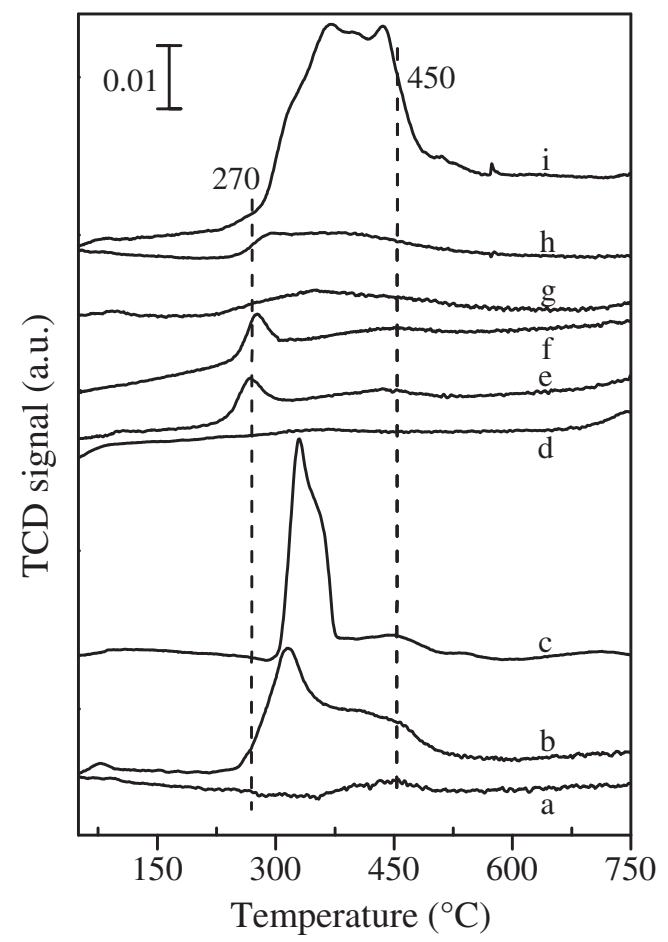

Figure 10. $\mathrm{H}_{2}$-TPR profiles of SBA-15 and M/SBA-15 calcined samples: (a) SBA-15, (b) V/SBA-15, (c) Cr/SBA15, (d) Mn/SBA-15, (e) Fe/SBA-15, (f) Co/SBA-15, (g) Ni/SBA-15, (h) Cu/SBA-15 and (i) Zn/SBA-15.

framework metal cations that are exposed on the pore wall surface are akin to impregnated metal-ion complexes on the pore walls of SBA-15. However these metal species, on subsequent interaction with surface hydroxyl groups contract the pore walls by combining with the neighbour hydroxyl groups, ${ }^{23}$ similar to silica cross-linking step during calcination process. Therefore surface framework metal cations facilitate pore shrinkage. On the contrary, the M/SBA-15 samples exhibited enhanced pore diameters compared to parent SBA-15 sample, ascertains the metal incorporation deep inside the pore walls. Moreover the thicker pore walls further supplements the interior location metal species.

SBA-15 does not show any reduction which illustrates the stronger silica framework which is shown in figure 10a. In general, the $3 \mathrm{~d}$ transition metal ions exist in either +2 or +3 oxidation states as they are stable oxidation states. The transition metal oxide particles employed in this study are usually reduced in the temperature range of $300-400^{\circ} \mathrm{C}$. However supported metal oxide clusters display higher reduction temperatures depend on different factors such as size of the metal oxide cluster, metal oxide to support interactions and location of metal species either isomorphically substituted well inside the silica matrix or extra framework. The broad reduction profiles exhibited by M/SBA-15 
samples between $250^{\circ} \mathrm{C}$ and $500^{\circ} \mathrm{C}$ indicate the presence of significant amount of metal oxide particles in different coordination environments. The absence of reduction temperature for $\mathrm{Mn} / \mathrm{SBA}-15$ sample (figure 10d) elucidate that the manganese is present as $\mathrm{Mn}^{+2}$ as it is more stable. Even though manganese exist as $\mathrm{Mn}^{+3}$ in aqueous solution, it easily disproportionate to $\mathrm{Mn}^{+2}$ and $\mathrm{MnO}_{2}$ as shown below.

$$
2 \mathrm{Mn}^{3+}+2 \mathrm{H}_{2} \mathrm{O} \rightleftharpoons \mathrm{Mn}^{2+}+\mathrm{MnO}_{2}(\mathrm{c})+4 \mathrm{H}^{+}
$$

The variation in the reduction temperatures is characteristic to corresponding metal species. Out of these metals studied, V, Cr and Fe tend to form oligomerization in aqueous solution under low $\mathrm{pH}$ conditions. But these isolated metal species are occluded in the micropore corona, and the high temperature reductions $\left(\sim 450^{\circ} \mathrm{C}\right)$ of M/SBA-15 are attributed to possible reduction of stable oligomeric metal oxide clusters.

\section{Conclusions}

The manipulation of interfacial curvature and topology plays a fundamental role in the creation of soft materials. The effect of inorganic salts on the structure and morphology of SBA-15 materials prepared by one-pot method has been studied. The physicochemical properties deduced from textural and structural characterizations such as BET sorption isotherms, XRD, SEM and TEM provide some insight into the P123 micelle aggregation and formation mechanism of silica network in the presence of metal salts under similar synthesis conditions of SBA-15. The incorporation of metal into the silica network is confirmed by the UV-vis DRS and $\mathrm{H}_{2}$-TPR analyses. The presence of metal salt promoted the cross-linking in silica as well as inducement of some curvature to different macroscopic morphologies of SBA-15 particles. The enlarged pore radii and thicker pore walls are observed in the presence of metal salt which are indeed useful in various catalytic processes.

\section{Acknowledgement}

Financial support from DRDO, New Delhi, through Grant ERIP/ER/0600319/M/01/1052 is gratefully acknowledged. We thank SERC division of DST, Ministry of Science and Technology, New Delhi, for providing experimental facilities under FIST schemes.

\section{References}

1. Gómez S, Garces L J, Villegas J, Ghosh R, Giraldo O and Suib S L 2005 J. Catal. 23360
2. Sapsford K E, Algar W R, Berti L, Gemmill K B, Casey B J, Oh E, Stewart M H and Medintz I L 2013 Chem. Rev. 1131904

3. Tang F, Li L and Chen D 2012 Adv. Mater. 241504

4. Nakanishi K and Tanaka N 2007 Acc. Chem. Res. 40 863

5. Wagner T, Haffer S, Weinberger C, Klaus D and Tiemann M 2013 Chem. Soc. Rev. 424036

6. Zhao D, Huo Q, Feng J, Chmelka B F and Stucky G D 1998 J. Am. Chem. Soc. 1206024

7. Charan P H K and Ranga Rao G 2013 J. Porous Mater. 2081

8. Wang L, Kong A, Chen B, Ding H, Shan Y and He M 2005 J. Mol. Catal. A: Chem. 230143

9. Charan P H K and Ranga Rao G 2014 Micropor. Mesopor. Mater. 200101

10. Prathap M U A, Kaur B and Srivastava R 2012 J. Coll. Interface Sci. $\mathbf{3 8 1} 143$

11. Mathew T, Sivaranjani K, Gnanakumar E S, Yamada Y, Kobayashia T and Gopinath C S 2012 J. Mater. Chem. 2213484

12. Ma Y, Qi L, Ma J, Wu Y, Liu O and Cheng H 2003 Coll. Surf. A: Physicochem. Eng. Aspects 2291

13. Zhao D, Sun J, Li Q and Stucky G D 2000 Chem. Mater. 12275

14. Lee H I, Kim J H, Stucky G D, Shi Y, Pak C and Kim J M 2010 J. Mater. Chem. 208483

15. Sayari A, Han B-H and Yang Y 2004 J. Am. Chem. Soc. 12614348

16. Zhao D, Feng J, Huo Q, Melosh N, Fredrickson G H, Chemelka B F and Stucky G D 1998 Science 279 548

17. Yu C, Fan J, Tian B and Zhao D 2004 Chem. Mater 16 889

18. Benamor T, Vidal L, Lebeau B and Marichal C 2012 Micropor. Mesopor. Mater. 153100

19. Zhang W-H, Zhang L, Xiu J, Shen Z, Li Y, Ying P and Li C 2006 Micropor. Mesopor. Mater. 89179

20. Zhai S-R, Park S S, Park M, Ullah M H and Ha C-S 2008 Micropor. Mesopor. Mater. 11347

21. Zhang H, Sun J, Ma D, Weinberg G, Su D S and Bao X 2006 J. Phys. Chem. B 11025908

22. Manet S, Lecchi A, Impéror-Clerc M, Zholobenko V, Durand D, Oliveira C L P, Pedersen O J S, Grillo I, Meneau F and Rochas C 2011 J. Phys. Chem. B 115 11318

23. Selvaraj M and Kawi S 2007 Chem. Mater. 19509

24. Selvaraj M and Park D W 2010 Appl. Catal. A: Gen. 388 22

25. Kumar G S, Palanichamy M, Hartmann $M$ and Murugesan V 2007 Catal. Commun. 8493

26. Wang Y, Yang W, Yang L, Wang X and Zhang Q 2006 Catal. Today 117156

27. Park Y, Kang T, Kim P and Yi J 2006 J. Colloid Interface Sci. 295464

28. Lee H S, Kim W H, Lee J H, Choi D J, Jeong Y-K and Chang J H 2012 J. Solid State Chem. 18589

29. Bérubé F and Kaliaguine S 2008 Micropor. Mesopor. Mater. 115469

30. Blin J L and Impéror-Clerc M 2013 Chem. Soc. Rev. 42 4071 